\title{
SHARPENING SOME CLASSICAL NUMERICAL RADIUS INEQUALITIES
}

\author{
Mohsen ERfanian Omidvar, Hamid Reza Moradi And Khalid Shebrawi
}

Abstract. New upper and lower bounds for the numerical radii of Hilbert space operators are given. Among our results, we prove that if $A \in \mathscr{B}(\mathscr{H})$ is a hyponormal operator, then for all non-negative non-decreasing operator convex $f$ on $[0, \infty)$, we have

$$
f(\omega(A)) \leqslant \frac{1}{2}\left\|f\left(\frac{1}{1+\frac{\xi_{|A|}^{2}}{8}}|A|\right)+f\left(\frac{1}{1+\frac{\xi_{|A|}^{2}}{8}}\left|A^{*}\right|\right)\right\|,
$$

where $\xi_{|A|}=\inf _{\|x\|=1}\left\{\frac{\left\langle\left(|A|-\left|A^{*}\right| x, x\right\rangle\right.}{\left\langle\left(|A|+\left|A^{*}\right|\right) x, x\right\rangle}\right\}$. Our results refine and generalize earlier inequalities for hyponormal operator.

Mathematics subject classification (2010): Primary 47A12, Secondary 47A30.

Keywords and phrases: Numerical radius, operator norm, hyponormal operator, AM-GM inequality.

\section{REFERENCES}

[1] A. ABU-OMAR, F. KitTANeH, Upper and lower bounds for the numerical radius with an application to involution operators, Rocky Mountain J. Math. 45 (2015), no. 4, 1055-1064.

[2] R. Bhatia, Matrix Analysis, Springer-Verlag, Berlin, 1997.

[3] S. S. DRAGomir, Some inequalities for the norm and the numerical radius of linear operators in Hilbert spaces, Tamkang J. Math. 39 (2008), no. 1, 1-7.

[4] M. FujiI, R. Nakamoto, Simultaneous extensions of Selberg inequality and Heinz-Kato-Furuta inequality, Nihonkai Math. J. 9 (1998), no. 2, 219-225.

[5] T. FuRUTA, Invitation to Linear Operators, Taylor \& Francis, Ltd., London, 2001.

[6] K. E. Gustafson, D. K. M. RAO, Numerical Range. The Field of Values of Linear Operators and Matrices, Springer-Verlag, New York, 1997.

[7] P. R. Halmos, A Hilbert Space Problem Book, 2nd ed., Springer, New York, 1982.

[8] O. Hirzallah, F. Kittaneh, K. Shebrawi, Numerical radius inequalities for commutators of Hilbert space operators, Numer. Funct. Anal. Optim. 32 (2011), no. 7, 739-749.

[9] O. Hirzallah, F. Kittaneh, K. Shebrawi, Numerical radius inequalities for certain $2 \times 2$ operator matrices, Integral Equations Operator Theory 71 (2011), no. 1, 129-147.

[10] L. HogBen (ED.), Handbook of Linear Algebra, Chapman \& Hall/CRC Press, Boca Raton, 2007.

[11] M. KiAn, Operator Jensen inequality for superquadratic functions, Linear Algebra Appl. 456 (2014), $82-87$.

[12] F. KitTANEH, A numerical radius inequality and an estimate for the numerical radius of the Frobenius companion matrix, Studia Math. 158 (2003), no. 1, 11-17.

[13] F. Kittaneh, Norm inequalities for certain operator sums, J. Funct. Anal. 143 (1997), no. 2, 337 348.

[14] F. Kittaneh, Numerical radius inequalities for Hilbert space operators, Studia Math. 168 (2005), no. $1,73-80$.

[15] K. Shebrawi, H. Albadawi, Numerical radius and operator norm inequalities, J. Inequal. Appl. (2009) Article ID 492154, 11 pages.

[16] K. SheBRAWI, Numerical radius inequalities for certain $2 \times 2$ operator matrices II, Linear Algebra Appl. 523 (2017), 1-12. 
[17] T. YAMAZAKI, On upper and lower bounds of the numerical radius and an equality condition, Studia Math. 178 (2007), 83-89.

[18] L. Zou, Y. JiANG, Improved arithmetic-geometric mean inequality and its application, J. Math. Inequal. 9 (2015), 107-111. 